\title{
BMJ Global Health Effectiveness of primary care gatekeeping: difference-in-differences evaluation of a pilot scheme in China
}

\author{
Jin Xu (D) , ${ }^{1}$ Timothy Powell-Jackson, ${ }^{2}$ Anne Mills ${ }^{2}$
}

To cite: Xu J, Powell-Jackson T, Mills A. Effectiveness of primary care gatekeeping: difference-in-differences evaluation of a pilot scheme in China. BMJ Global Health 2020;5:e002792. doi:10.1136/ bmjgh-2020-002792

Handling editor Seye Abimbola

- Additional material is published online only. To view please visit the journal online (http://dx.doi.org/10.1136/ bmjgh-2020-002792).

Received 1 May 2020 Revised 9 July 2020 Accepted 14 July 2020
D Check for updates

(c) Author(s) (or their employer(s)) 2020. Re-use permitted under CC BY-NC. No commercial re-use. See rights and permissions. Published by BMJ.

${ }^{1}$ China Center for Health Development Studies, Peking University, Beijing, China ${ }^{2}$ Department of Global Health and Development, Faculty of Public Health and Policy, London School of Hygiene \& Tropical Medicine, London, UK

Correspondence to

Dr Jin Xu; xujin@hsc.pku.edu.cn

\section{ABSTRACT}

Introduction This paper evaluates the effectiveness of a gatekeeping pilot in shifting resources and patient visits from hospitals to primary care facilities under the Chinese New Rural Cooperative Medical Scheme.

Methods We applied a difference-in-differences regression analysis using claims data from a pilot district in northern China. The study covered 200685 enrollees in 17 townships in 2012 and followed-up the townships over 12 year-quarters until the end of 2014.

Results The gatekeeping pilot led to significantly more patients visiting primary care facilities $(55.3 \%$, $p=0.001$ ), but there was little evidence of increased ambulatory spending on primary care $(1.6 \%, \mathrm{p}=0.884)$. The pilot reduced hospital visits by $23.9 \%(p=0.048)$ and ambulatory spending at the hospitals by $22.4 \%(p=0.011)$. Conclusions This first impact evaluation of gatekeeping outside high-income countries found that gatekeeping policy did not seem to have expanded the care provided by primary care facilities, despite an increased volume of claimed visits. Although claimed patient visits and expenditure at hospitals reduced, we suspect this may have been because patients found it either cumbersome or difficult to obtain reimbursement for their care.

\section{INTRODUCTION}

Strong primary care is viewed as the corner stone of well-performing health systems. ${ }^{1}$ Countries with better resourced primary care tend to have better-population health and health system efficiency. ${ }^{2-4}$ Within countries, primary care is associated with lower population mortality rates. ${ }^{56}$ Primary care has also been demonstrated as a sound platform for cost-effective services that could reduce the need for expensive specialist care. ${ }^{7} \mathrm{WHO}$ and United Nations International Children's Emergency Fund have repeatedly committed to a health system model based on primary healthcare, most recently in the Astana Declaration on primary healthcare in the context of universal health coverage and the Sustainable Development Goals. ${ }^{8} 9$ Nonetheless, patients in low-income and middle-income countries often bypass primary care facilities

\section{Key questions}

What is already known?

- Patients in low-income and middle-income countries often bypass primary care, thus restricting its actual contribution.

- Previous studies on gatekeeping focused on highincome countries and reported mixed findings regarding its effects on utilisation and expenditure.

- Two recent studies from China suggest that lowering user fees for primary care and increasing user fees for hospital ambulatory care can shift some patient visits from hospitals to primary care facilities.

\section{What are the new findings?}

- This first impact evaluation of gatekeeping in a low-income and middle-income country suggests the ineffectiveness of gatekeeping in increasing expenditure on primary care facilities, despite an increased volume of visits claimed.

- Gatekeeping reduced claimed patient visits and expenditure at hospitals, though we suspect that many ambulatory visits to hospitals might have continued but without reimbursement.

\section{What do the new findings imply?}

- Gatekeeping may reduce claimed visits to and expenditure at hospitals, but unlikely to strengthen the range of care of primary care facilities.

- The limited effects of the pilot question the relevance of gatekeeping alone as a reform in the current Chinese context.

- Further study needs to see whether the patients suffer more out-of-pocket expenditure unclaimed because of gatekeeping.

to seek care directly at secondary and tertiary hospitals ${ }^{10}$ which suggests that these health systems are not working as intended.

China has encountered challenges of a weak primary care sector amid its muchpraised effort to provide basic healthcare coverage to everyone launched in $2009 .{ }^{11} 12$ Primary care in China comprises township health centres and village clinics in rural areas and community health centres and stations in urban areas. The government has 
tried multiple ways to strengthen primary care infrastructure, staff quality and financial access. However, there have been substantial gaps between primary care facilities and (district and tertiary) hospitals in China in terms of resources and service utilisation. Partially owing to substantially lower remuneration for primary care staff, such staff often lack full medical training and are licensed as assistant doctors, in contrast to the generally fully qualified staff at tertiary and district hospitals. ${ }^{13-15}$ The role of village clinics staffed with village doctors (licensed below the level of assistant doctors) in health centres has been reported to be shrinking. ${ }^{16}$ The Chinese population enjoys unrestricted access to hospitals, almost all of which operate direct-access outpatient departments. Since the 2009 reform, the hospital share of patient visits and health expenditure has continued to increase, with hospital bed numbers also increasing rapidly, ${ }^{17}$ and total hospital expenditure was about six times higher than total primary care facility expenditure in $2017 .^{14}$

A gatekeeping policy is frequently proposed to channel patients to primary care facilities as their first point of contact with the health system. ${ }^{10}{ }^{18}$ Under gatekeeping, patients need to be referred by a primary care practitioner in order to access specialist care. A recent systematic review of the effectiveness of gatekeeping ${ }^{19}$ found mixed results in terms of quality of care, health outcomes, utilisation and expenditure, with findings seemingly dependent on context. These studies were all done in high-income countries, where, unlike in China, primary care is provided by doctors specialised in primary care with a level of professional qualifications similar to those of hospital specialists. Therefore, these findings are likely to have limited relevance to China.

With the recent expansion of social health insurance schemes in China, strategic purchasing arrangements are being used to channel patient visits to primary care facilities. This paper reports findings from an assessment of the impact of a gatekeeping pilot in the context of a rural social health insurance scheme in northern China. The main question is whether the introduction of gatekeeping in an insurance scheme shifted resources (total expenditures) and patient visits from hospitals to primary care facilities. Although this paper is primarily a quantitative evaluation, we also draw in interpreting the findings on qualitative evidence from a related study reported elsewhere. $^{13}$

\section{METHODS}

\section{Study design and setting}

The gatekeeping pilot was a complex intervention implemented at the level of a township and seeking to make direct care seeking at hospitals less desirable and so shift ambulatory care from hospitals to primary care facilities. It was complex as it involved multifaceted policy changes in the functioning of the insurance scheme. We examined the effect of the gatekeeping pilot by using a differencein-differences approach, in which we compared changes in outcomes in the gatekeeping townships with changes in outcomes in comparison townships.

The setting was a semirural district of a large metropolitan city in northern China, within the context of the New Rural Cooperative Medical Scheme (NCMS). The NCMS is a nationwide public health insurance scheme launched in 2003 that had covered over $98 \%$ of the eligible population by 2012. ${ }^{20}$ NCMS funds are pooled and managed at the district/county level. The district we studied had a population of about 0.4 million, slightly less than half of whom were rural residents. Rural 2012 per capita income was 16865 yuan (2012-2014 average exchange rate: Yuan 1=US\$0.161). More than 99\% of the eligible population were enrolled in the NCMS, amounting to 200685 enrollees in 2012. Over the 3 years between 2012 and 2014, each enrollee paid a premium contribution of 100 yuan every year and participated through the unit of a household, and government subsidy in the premium increased from 540 to 900 yuan/year.

The local NCMS covered a comprehensive range of benefits equivalent to those enjoyed by urban employees, with cost sharing by patients in the form of deductibles and partial reimbursement of fees. The district NCMS fund allowed a lower deductible (100 yuan vs 500 yuan) and higher reimbursement rate $(50 \%$ vs $35 \%$ or $30 \%)$ for visits to primary care facilities compared with hospital visits to encourage the use of primary care facilities. Ambulatory services for some high-cost treatments (such as radiotherapy and chemotherapy for cancers) that took place mainly in hospitals had higher reimbursement rates, which also varied by level of health facilities. Enrollees paid their ambulatory expenditure in full at health facilities, and village cadres collected patients' receipts, brought them to the township financial department for settlement and gave the reimbursement to patients. Through support from the Medical Financial Assistance programme, people living on a subsistence allowance were eligible for a reduction or waiver of outof-pocket fees.

Almost all doctors working in the rural primary care facilities lacked full university medical degrees and were certified as either licensed assistant physicians or village doctors, whereas most hospital doctors had university degrees and all were fully certified licensed physicians. ${ }^{13}$ In our study area, village clinics played a marginal role in ambulatory care and were mainly staffed by public health agents. ${ }^{13}$ Hence, patients relied on their local township health centres, district hospitals, as well as municipal higher-level hospitals outside the district (referred to below as 'tertiary hospitals') for medical services.

Between July 2013 and December 2014, the pilot reform was implemented in 2 townships (ie, subdistricts) among the 17 townships. The pilot programme introduced both demand-side and supply-side changes to shift ambulatory patient visits and service expenditures from hospitals to primary care providers. On the demand side, patients with non-emergency conditions in the pilot townships needed to obtain a referral letter 
from primary care facilities to access care at ambulatory departments of district hospitals and from district hospitals to access ambulatory departments of higherlevel hospitals. Patients could effectively opt out of gatekeeping by paying out-of-pocket at these hospitals. On the supply side, the township health centres in pilot townships became fundholders and were given an annual global budget for all ambulatory services reimbursement to their local NCMS enrollees. The budget was calculated according to the level of ambulatory reimbursement per enrollee in 2012 (235 yuan in one township and 133 yuan in the other), with a $5 \%$ year-on-year increment. The two township health centres retained the surplus or deficit for each financial year and could decide how to allocate a potential surplus. The expectation was that township health centres (and the village clinics below them) would wish to treat patients rather than refer to hospitals. Hence, if the pilot worked as intended, there would be an increase in primary care utilisation and a reduction in hospital ambulatory care utilisation and some reallocation of reimbursement amounts from hospitals to primary care facilities.

The gatekeeping pilot did not explicitly require a change in the scope of services provided by primary care providers. In theory, the primary care providers were supposed to manage most of the common illnesses of the catchment population (including particularly prevalent non-communicable diseases such as hypertension and diabetes); in reality their scope was limited by lack of technical capacity as well as patients' lack of trust in service quality. ${ }^{13}$ As was common elsewhere in China, there was no specific guideline on what cases should be treated in primary care and what referred to hospitals. During our fieldwork on the implementation of the gatekeeping pilot, the local NCMS manager explained to the primary care providers informally that in most cases, they should refer only when the clinical condition was clearly outside their technical capacity and 'could not be treated after two visits'.

\section{Data and study outcomes}

We acquired data on claims and enrolment for all NCMS enrollees in the district's 17 townships from the Municipal Management Centre of the NCMS for the period 1 January 2012 -31 December 2014. This 3-year period included 18 months before the introduction of gatekeeping in the two townships and the first 18 months of its implementation. During the study period, patients had to pay their ambulatory expenditure in full at health facilities and village cadres collected patients' receipts and submitted them to township financial offices, where eligible expenditures were reimbursed into savings accounts of the patients with claims information manually entered into township claims databases. The claims database recorded each claimed episode of patient care, including total amount of expenditure, amount reimbursed to the patient, amount of expenditure not covered by the NCMS, name and level of the facility, date of visit and characteristics of the patient (age, gender, personal identification number, and village and township of residence).

Using the claims data, for each enrollee, we generated the following outcomes: number of ambulatory visits at primary care facilities, district hospitals and tertiary hospitals, respectively, per quarter; and ambulatory expenditures at primary care facilities, district hospitals and tertiary hospitals, respectively, per quarter. We then aggregated the data by the quarter of the year and township for analysis. We used the available personal characteristics aggregated at the township level (mean age and proportion of female individuals) as covariates.

\section{Statistical analysis}

Difference-in-differences (DiD) regression analysis ${ }^{21}$ was used to estimate the effects of the pilot, with the two pilot townships serving as a treatment group and the 15 others as a comparison group. Such quasi-experimental methods are increasingly used in the evaluation of the impacts of complex interventions. ${ }^{22} 23$ Our analytical models allowed for flexible time trends using a binary variable for each quarter year and allowed for time-invariant differences between townships by including a binary variable for each township. In addition, we controlled for characteristics of the township, including proportion of female enrollees and mean age. Specifications of empirical models are provided in the online supplementary appendix 1 . We clustered standard errors at the township level. We ran a pretrend test to check for potential differences in the prepilot trends of visits and expenditures between pilot and non-pilot areas. We were unable to reject the null hypothesis of a difference in pretrends (see the online supplementary appendix 2). We used Stata V.15.1 for the analysis.

\section{Patient and public involvement}

We did not directly engage patients or the public in the development of the research question and outcome measures. Our research question was informed by the importance of primary care in contributing to population health demonstrated in previous studies, as well as the suggested importance of gatekeeping in maintaining the function of primary care in both research papers and policy debates. Our outcome measures were selected to reflect patients' actual care-seeking behaviours in terms of overall expenditures and visits. This allowed the study to explore the patients' priorities, experience and preferences regarding care seeking in response to the gatekeeping pilot and to feed such information back to policymakers, who may improve policies to better respond to patient needs and preferences.

The paper relies on claims data. Patients were not involved in the recruitment to or conduct of the study. A preliminary version of the results has already been communicated to the local policy-makers. This study is not a randomised trial. It is an observatory in its nature, as we had not participated in the development of the 
Table 1 Baseline characteristics of enrollees and facilities in pilot and non-pilot townships (2012)

\begin{tabular}{|c|c|c|c|c|c|c|c|}
\hline & \multicolumn{2}{|l|}{ Pilot } & \multicolumn{2}{|l|}{ Non-pilot } & \multirow[b]{2}{*}{$\mathbf{t}$} & \multirow[b]{2}{*}{$P$ value } & \multirow[b]{2}{*}{ Observations (n } \\
\hline & Mean & SD & Mean & SD & & & \\
\hline Townships (n) & 2 & - & 15 & - & - & - & 17 \\
\hline \multicolumn{8}{|l|}{ Population } \\
\hline Total number & 4434 & 1033 & 27001.6 & 5931.179 & 1.351 & 0.197 & 17 \\
\hline Rural percentage & 81.8 & 1.22 & 70.2 & 5.05 & -0.813 & 0.429 & 17 \\
\hline \multicolumn{8}{|l|}{ Enrollees } \\
\hline Total number & 3529 & 748 & 12787.8 & 1356.52 & 2.420 & 0.029 & 17 \\
\hline Mean age & 46.9 & 0.34 & 45.6 & 0.37 & -1.284 & 0.219 & 17 \\
\hline Females (\%) & 51.5 & 0.01 & 51.5 & 0.01 & 0.050 & 0.961 & 17 \\
\hline \multicolumn{8}{|l|}{ Township health centres } \\
\hline Number of beds & 4 & . & 15.1 & 1.70 & . & . & 15 \\
\hline Staff number & 19 & 2.00 & 70.6 & 8.09 & 2.264 & 0.039 & 17 \\
\hline Health professionals & 15.5 & 1.50 & 58.5 & 6.32 & 2.412 & 0.029 & 17 \\
\hline Doctors & 4 & 3.00 & 32.3 & 4.12 & 2.438 & 0.028 & 17 \\
\hline Fully certified doctors & 1.5 & 0.50 & 25.5 & 4.10 & 2.077 & 0.055 & 17 \\
\hline Nurses & 1 & 0 & 10.9 & 1.86 & 1.882 & 0.079 & 17 \\
\hline
\end{tabular}

intervention, nor did we assign the participants to treatment or control groups. All decisions had been made by the local government officials. As a result, the study represented a potential mechanism to collect important information on the actual response of patients to the gatekeeping policy. The results will be further communicated with policy-makers in China at both central and local levels, including those in the pilot area, and disseminated to the public through social media.

\section{RESULTS}

As shown in table 1, the two pilot townships had, on average, a smaller number of enrollees (3529 vs 12788) and a higher percentage of rural household residents $(81.8 \%$ vs $70.2 \%)$ compared with the non-pilot townships. They had a similar percentage of female individuals $(46.9 \%$ in pilot townships vs $45.6 \%$ in non-pilot townships). The pilot townships had township health centres of considerably smaller staff size, corresponding to their smaller population.

Table 2 presents the average number of visits per enrollee per quarter in the pilot and non-pilot townships before and after the launch of the pilot, as well as results of the $\mathrm{DiD}$ analysis. Average ambulatory visits in primary care facilities per enrollee per quarter increased from 0.257 to 0.539 in pilot townships, as compared with from 0.187 to 0.306 in non-pilot townships. DiD analysis estimated a significant positive effect of 0.142 primary care visits per enrollee per quarter (95\% CI 0.071-0.212, $\mathrm{p}=0 \cdot 001)$. Visits per enrollee per quarter to all hospitals fell from 0.109 before gatekeeping to 0.09 per enrollee per quarter after gatekeeping, in comparison with an increase from 0.187 to 0.306 in non-pilot townships during the same period. The DiD analysis estimated an effect of $-0.026(95 \%$ CI -0.051 to $-0.001, p=0 \cdot 041)$ fewer hospital visits per enrollee per quarter. Within hospitals,

Table 2 Effect of gatekeeping on ambulatory care visits per enrollee per quarter $(n=204)$

\begin{tabular}{|c|c|c|c|c|c|c|}
\hline \multirow[b]{2}{*}{ Facility type } & \multicolumn{2}{|c|}{$\begin{array}{l}\text { Before the introduction of } \\
\text { gatekeeping }\end{array}$} & \multicolumn{2}{|c|}{$\begin{array}{l}\text { After the introduction of } \\
\text { gatekeeping }\end{array}$} & \multirow[b]{2}{*}{$\begin{array}{l}\text { Difference-in-differences effect } \\
(95 \% \mathrm{Cl})\end{array}$} & \multirow[b]{2}{*}{ P value } \\
\hline & Pilot $(n=12)$ & $\begin{array}{l}\text { Comparison } \\
(\mathrm{n}=90)\end{array}$ & $\begin{array}{l}\text { Pilot } \\
(n=12)\end{array}$ & $\begin{array}{l}\text { Comparison } \\
(\mathrm{n}=90)\end{array}$ & & \\
\hline $\begin{array}{l}\text { Primary care } \\
\text { facilities }\end{array}$ & $0.257(0.201)$ & $0.187(0.126)$ & $0.539(0.199)$ & $0.306(0.136)$ & 0.142 (0.071 to 0.212$)$ & 0.001 \\
\hline Hospitals & $0.109(0.092)$ & $0.105(0.062)$ & $0.090(0.052)$ & $0.115(0.054)$ & $-0.026(-0.051$ to 0.001$)$ & 0.040 \\
\hline $\begin{array}{l}\text { District } \\
\text { hospitals }\end{array}$ & $0.097(0.084)$ & $0.092(0.053)$ & $0.082(0.046)$ & $0.102(0.047)$ & $-0.024(-0.047$ to 0.000$)$ & 0.048 \\
\hline $\begin{array}{l}\text { Tertiary } \\
\text { hospitals }\end{array}$ & $0.012(0.010)$ & $0.013(0.010)$ & $0.008(0.006)$ & $0.013(0.008)$ & $-0.003(-0.005$ to 0.000$)$ & 0.031 \\
\hline
\end{tabular}

$\mathrm{SD}$ in parentheses. 
Table 3 Effect of gatekeeping on ambulatory care expenditure per enrollee per quarter $(n=204)$

\begin{tabular}{|c|c|c|c|c|c|c|}
\hline \multirow[b]{2}{*}{ Facility type } & \multicolumn{2}{|c|}{$\begin{array}{l}\text { Before the introduction of } \\
\text { gatekeeping }\end{array}$} & \multicolumn{2}{|c|}{$\begin{array}{l}\text { After the introduction of } \\
\text { gatekeeping }\end{array}$} & \multirow[b]{2}{*}{$\begin{array}{l}\text { Difference-in-differences effect } \\
(95 \% \mathrm{Cl})\end{array}$} & \multirow[b]{2}{*}{$P$ value } \\
\hline & $\begin{array}{l}\text { Pilot } \\
(n=12)\end{array}$ & $\begin{array}{l}\text { Comparison } \\
(n=90)\end{array}$ & $\begin{array}{l}\text { Pilot } \\
(n=12)\end{array}$ & $\begin{array}{l}\text { Comparison } \\
(n=90)\end{array}$ & & \\
\hline $\begin{array}{l}\text { Primary care } \\
\text { facilities }\end{array}$ & $49.814(50.253)$ & $57.142(40.806)$ & $63.775(34.647)$ & $70.722(26.010)$ & $0.840(-11.126$ to 12.806$)$ & 0.884 \\
\hline Hospitals & $100.674(100.687)$ & $87.923(58.950)$ & $91.747(56.832)$ & $105.349(46.604)$ & $-22.600(-139.167$ to 6.034$)$ & 0.011 \\
\hline $\begin{array}{l}\text { District } \\
\text { hospitals }\end{array}$ & 69.487 (70.101) & $67.393(45.062)$ & $76.023(46.728)$ & 84.169 (36.630) & $-7.132(-16.225$ to 1.961$)$ & 0.100 \\
\hline $\begin{array}{l}\text { Tertiary } \\
\text { hospitals }\end{array}$ & $31.187(34.495)$ & $20.530(16.151)$ & $15.724(11.616)$ & $21.180(11.247)$ & $-15.317(-125.254$ to 5.379$)$ & 0.005 \\
\hline
\end{tabular}

SD within parentheses.

visits to district hospitals in pilot townships fell from 0.097 to 0.082 per enrollee per quarter compared with an increase of 0.01 per enrollee per quarter in non-pilot townships. We estimated that the pilot led to a significant reduction of -0.024 visits to district hospitals per enrollee per quarter ( $95 \%$ CI -0.047 to $0, p=0.048$ ). Visits to tertiary hospitals also fell in pilot townships from 0.012 to 0.008 per enrollee per quarter, whereas visits to tertiary hospitals in non-pilot townships remained unchanged. The estimated effect of gatekeeping on tertiary hospital visits based on the DiD analysis was significant $(95 \%$ CI -0.005 to $0, p=0.040$ ) at -0.003 visits per enrollee per quarter. Trendline figures of visits by levels of care per enrollee per quarter in the pilot and non-pilot townships for additional reference in the online supplementary appendix 3.

As shown in table 3, total ambulatory expenditure at primary care facilities in pilot townships per enrollee per quarter increased from 49.814 to 63.775 yuan, as compared with a less substantial increase from 57.142 to 80.722 yuan in non-pilot townships. The DiD analysis estimated a small insignificant increase of 0.840 yuan $(95 \% \mathrm{CI}$ -11.126 to $12.806, \mathrm{p}=0 \cdot 884$ ) in ambulatory expenditure at primary care per enrollee per quarter due to the pilot. The ambulatory expenditure at hospitals per enrollee per quarter in the pilot townships decreased from 100.674 to 91.747 yuan, as compared with an increase from 87.923 to 105.349 yuan in non-pilot townships. The estimated DiD effect of the gatekeeping pilot was a significant reduction of $22.6(95 \%$ CI -39.167 to $-6.034, \mathrm{p}=0.011)$ yuan per enrollee per quarter. The reduction in spending at hospitals was driven by tertiary hospitals. Trendline figures of expenditures by levels of care per enrollee per quarter in the pilot and non-pilot townships are provided for additional reference in the online supplementary appendix 3.

\section{DISCUSSION}

\section{Summary and discussion about results}

The findings from the study suggested that the gatekeeping pilot led to a substantial increase of 0.142 visits per enrollee per quarter to primary care facilities or
$55.3 \%$ of the mean level of primary care visits in pilot townships before gatekeeping. We also found that visits to hospitals per enrollee per quarter fell by a significant -0.026 ( -10.026 for district hospitals and -0.024 tertiary hospitals), which amounted to $-23.9 \%$ of the mean level of hospital visits in pilot townships before gatekeeping. However, the increased visits to primary care facilities per enrollee per quarter (0.142) far outweighed the decreased visits to district hospitals $(-0.024)$ and tertiary hospitals $(-0.003)$.

Surprisingly, there was no evidence that the gatekeeping pilot increased expenditures at primary care facilities. Although there was also no indication of any change in spending at district hospitals, there was strong evidence that the pilot decreased spending at tertiary hospitals, by -15.317 yuan per enrollee per quarter. Overall, there was a significant reduction of overall spending in hospitals by -22.6 yuan per enrollee per quarter, which was by about $-22.4 \%$ of mean hospital spending in pilot townships before gatekeeping.

Thus, although the pilot led to a substantial increase in primary care visits, it led to no significant increase in primary care spending. Our earlier, qualitative, study suggested that many patients came to primary care facilities only to get referral letters, so they could get some spending at the hospital level reimbursed. ${ }^{13}$ The reduction in visits and health expenditure at hospitals appeared to be the effects of successful gatekeeping. However, based on our qualitative work, ${ }^{13}$ as the gatekeeping pilot made it more difficult for patients to use their insurance coverage to access hospitals, some patients might simply have resorted to paying out-of-pocket to access hospital care and not claiming reimbursement. Therefore, the reduction of hospital visits and spending after the gatekeeping pilot might alternatively reflect a decrease in recorded rather than actual visits to and expenditure at all hospitals. Overall, it seems that the pilot policy did not expand the care provided by primary care facilities, and we suspect that ambulatory visits to hospitals continued but with some reimbursement not claimed, so changes in visits and expenditure were not visible in the claims database. 


\section{Strengths and limitations}

Our methods have several strengths. First, we used NCMS claims data that avoided the potential recall bias likely to be found in household surveys. Second, our study used DiD in estimating treatment effects. This was an improvement on previous studies, which mainly used crosssectional, cross-country ecological study design or beforeand-after without control, ${ }^{24}$ as well as Chinese studies on the effects of changes of cost sharing on primary care utilisations. ${ }^{25}$ Our use of a comparison group reduced the risk of attribution of temporal changes unrelated to gatekeeping. Of note, the $\mathrm{DiD}$ approach attributes any difference in trends between the treatment and control groups to the effects of the intervention, so may be problematic in situations where treatment (ie, policy) has changed over time or where the parallel pretrends assumption was violated. As shown in the online supplementary appendix 2, the results of our test for pretrends suggest that the DiD approach is reasonable. Although unobserved confounding always poses a threat to the DiD approach, earlier qualitative findings that policies other than gatekeeping were comparable across both pilot and non-pilot townships ${ }^{13}$ strengthens our confidence in the results of the $\mathrm{DiD}$ analysis. Third, the patients were not able to select which group to participate in, therefore reducing the risk of selection bias seen in previous studies using cross-sectional or before-and-after designs. ${ }^{19}$

Nevertheless, there are still some important limitations in our study that should be taken into consideration when considering its implications. First, the ability to generalise from our findings is limited as our samples were restricted to NCMS enrollees from a single district. The fact that the pilot townships and their township health centres were much smaller than non-pilot ones means that we need to be cautious in generalising the findings from this study. The pilot was started in relatively smaller townships possibly because policy-makers lacked confidence in primary care providers' capacity to function as gatekeepers and/or wished to minimise potential unintended consequences.

Second, our results on the effectiveness of gatekeeping were situated within the wider policy context in the area. After the implementation of the pilot, township health centres in pilot areas received a small amount of additional revenue from the surplus of the capitation budget, amounting to, on average, $3.3 \%$ of total ambulatory expenditure at primary care providers. As the overall salary bill was essentially fixed, ${ }^{13}$ this fund could be used only for non-salary expenses, such as improving working conditions, and not for financial incentives for staff to incentivise treatment of patients or to attract more higher trained doctors. As the substantial salary gaps between primary care providers and hospitals seemed to be a key issue contributing to difficulties in attracting and retaining capable staff at primary care facilities, ${ }^{13}$ this constraint might have limited the pilot's impact. An alternative pilot design that permitted using surplus for staff might have produced more positive results without threatening hospitals as these patients were not their main customers. However, large-scale scale gatekeeping could potentially activate hospital-related interests.

Third, the claims database had its limitations. The claims data were regularly generated and checked by claims processors; however, as bills were processed manually during the study period, claims processors sometimes combined multiple episodes of visits to a particular facility into a single claim. Such bundled claiming would imply that the actual change in the number of visits might have been substantially larger, though the spending at each level would likely remain the same. We also lacked information about expenditures (and their corresponding visits) not claimed.

Fourth, we were not able to control for diagnosis and socioeconomic status of enrollees, due to lack of available data of good quality.

\section{Comparison with the existing literature}

Our study has contributed fresh evidence to the current understanding of primary care's capacity to act as a gatekeeper or provider of first-contact care in China. The existing literature is very limited and mainly focuses on urban areas. A study of urban community health centres in two megacities of Shanghai and Shenzhen ${ }^{26}$ reported that an additional capitation budget has improved the perceived quality of first-contact care and primary care in general. A study in Luohu (a district in the Guangdong province of China), where the salary of general practitioners has been raised substantially, reported increased visits to primary care. ${ }^{27}$ Findings from recent reforms in two well-off cities ${ }^{25} 28$ also suggested that lowering user fees for primary care and increasing user fees for hospital ambulatory care may shift some patients away from hospitals to primary care facilities.

\section{Implications for practice and research}

Given that primary care is weak throughout China, the limited effects of the pilot question the relevance of gatekeeping as a reform option. The main barrier to greater success was almost certainly the lack of service capacity and patient trust in primary care providers. ${ }^{13}$ Introducing gatekeeping before improving the quality of primary care to be competitive with that of hospital care is unlikely to result in effective care provision at the primary care level. Given the huge inter-related gaps in staff pay and qualifications between primary care facilities and hospitals, primary care strengthening in China fundamentally requires substantially increased remuneration and higher-level qualifications for primary care professionals. This will require financial allocations to primary care facilities to reflect population health needs rather than historical expenditures or local patient ability to pay.

One way to make progress may be to start with improving treatment at the primary care level for specific diseases, with support from high-level hospitals through the lending of specialists and establishing referral partnerships, and more targeted capacity building of primary 
care providers. The strong financial incentives for hospitals to attract and retain patients also need addressing, with payment methods for services for a total population aligned with primary care strengthening and population health goals. ${ }^{13}$

With respect to the findings from this specific study, further research would benefit from having available household survey data to explore whether or not gatekeeping shifts spending to out-of-pocket payment.

\section{CONCLUSIONS}

Gatekeeping has been frequently proposed but understudied. This first impact evaluation of gatekeeping outside high-income countries, in the context of rural social health insurance in China, found that gatekeeping increased patient visits to primary care providers, but did not increase expenditure at that level. The study speculates, based on qualitative evidence, that this may have been because many of these additional primary care patients were visiting for a referral letter. The pilot led to a reduction of hospital visits and expenditures recorded in the claims database, but we suspect this may have been because patients found it either cumbersome or difficult to obtain reimbursement for their care. Introducing gatekeeping before improving primary care quality is unlikely to be effective in creating a primary care-centred health system.

Contributors JX conceived and designed the study under the supervision of AM and TP-J. JX collected and analysed the data and interpreted the results; wrote the first draft. AM and TP-J provided critical guidance and comments from on data analysis and result interpretation; provided critical intellectual comments and edits on the revision of the draft. All authors reviewed and approved the final submission.

Funding This paper was funded by the China Scholarship Council (No. 201206010317), and Natural Science Foundation of China (No. 71804004). The study formed part of Jin Xu's PhD study at the Department of Global Health and Development, Faculty of Public Health and Policy, London School of Hygiene \& Tropical Medicine, London, United Kingdom.

Competing interests None declared.

Patient and public involvement Patients and/or the public were not involved in the design, or conduct, or reporting, or dissemination plans of this research.

Patient consent for publication Not required.

Ethics approval Ethical approval for this study was provided by the Institutional Review Board for Biomedical Ethics at Peking University (IRB00001052-14024MIAN) and the Research Ethics Committee at the London School of Hygiene \& Tropical Medicine (PR/123/123).

Provenance and peer review Not commissioned; externally peer reviewed.

Data availability statement Data may be obtained from a third party and are not publicly available. The data used is deidentified participant data and available from the Municipal Office of New Cooperative Medical Scheme of the city where the pilot reform was conducted. Due to agreement, the name of the city and the data cannot be disclosed publicly.

Open access This is an open access article distributed in accordance with the Creative Commons Attribution Non Commercial (CC BY-NC 4.0) license, which permits others to distribute, remix, adapt, build upon this work non-commercially, and license their derivative works on different terms, provided the original work is properly cited, appropriate credit is given, any changes made indicated, and the use is non-commercial. See: http://creativecommons.org/licenses/by-nc/4.0/.

ORCID iD

Jin Xu http://orcid.org/0000-0002-6364-0887

\section{REFERENCES}

1 World Health Organization. The world health report 2008: primary health care: now more than ever. Geneva: World Health Organization, 2008.

2 Starfield B. Is primary care essential? Lancet 1994;344:1129-33.

3 Macinko J, Starfield B, Shi L. The contribution of primary care systems to health outcomes within organization for economic cooperation and development (OECD) countries, 1970-1998. Health Serv Res 2003;38:831-65.

4 Macinko J, Starfield B, Erinosho T. The impact of primary healthcare on population health in low- and middle-income countries. J Ambul Care Manage 2009;32:150-71.

5 Liang S, Macinko J, Yue D, et al. The impact of the health care workforce on under-five mortality in rural China. Hum Resour Health 2019;17:21

6 Basu S, Berkowitz SA, Phillips RL, et al. Association of primary care physician supply with population mortality in the United States, 2005-2015. JAMA Intern Med 2019;179:506-14.

7 Walker S, Mason AR, Claxton K, et al. Value for money and the quality and outcomes framework in primary care in the UK NHS. Br J Gen Pract 2010;60:e213-20.

8 World Health Organization, United Nations International Children's Emergency Fund. Declaration of Alma-Ata. International Conference on primary health care Kazakhstan. WHO, 1978.

9 World Health Organization. Declaration of Astana. Geneva: World Health Organization, 2018.

10 Hort K, Gilbert K, Basnayaka P, et al. Strategies to strengthen referral from primary care to secondary care in low- and middle-income countries, 2019.

11 Meng Q, Fang $\mathrm{H}$, Liu X, et al. Consolidating the social health insurance schemes in China: towards an equitable and efficient health system. Lancet 2015;386:1484-92.

12 Meng Q, Mills A, Wang L, et al. Health system reform: experiences and lessons from China. BMJ 2019.

$13 \mathrm{Xu}$ J, Mills A. Challenges for gatekeeping: a qualitative systems analysis of a pilot in rural China. Int J Equity Health 2017;16:106.

$14 \mathrm{Xu} \mathrm{J}$, Mills A. The rise of hospital dominance in China: distribution of resources and activities between hospitals and primary care facilities (1949-2018), 2019

15 Hsieh C-R, Tang C. The multi-tiered medical education system and its influence on the health care market-China's Flexner report. Hum Resour Health 2019;17:50.

16 Zhou XD, Li L, Hesketh T, et al. Health system reform in rural China: voices of healthworkers and service-users. Soc Sci Med 2014;117:134-41.

$17 \mathrm{Xu} \mathrm{J}$, Jian W, Zhu K, et al. Reforming public hospital financing in China: progress and challenges. BMJ 2019;365:14015.

18 World Bank Group, World Health Organization, Ministry of Finance, National Health and Family Planning Commission, Ministry of Human Resources and Social Security. Deepening health reform in China, building high-quality and value-based service delivery. Washington, DC, 2019.

19 Sripa P, Hayhoe B, Garg P, et al. Impact of GP gatekeeping on quality of care, and health outcomes, use, and expenditure: a systematic review. Br J Gen Pract 2019;69:e294-303.

20 National Health and Family Planning Commission. China health and family planning statistical Yearbook 2013, 2013.

21 Angrist JD, Pischke J-S. Parallel worlds: fixed Exects, Diderencesin-differences, and panel data. mostly harmless Econometrics: an Empiricist's companion. Princeton University Press: Princeton, NJ, 2009.

22 Dimick JB, Ryan AM. Methods for evaluating changes in health care policy: the difference-in-differences approach. JAMA 2014;312:2401-2.

23 Craig P, Cooper C, Gunnell D, et al. Using natural experiments to evaluate population health interventions: new medical Research Council guidance. J Epidemiol Community Health 2012;66:1182-6.

24 Ose D, Broge B, Riens B, et al. Contacts to specialists with referrals by GP-Have GP centred health care $(\mathrm{HZV})$ contracts an impact? Zeitschrift fur Allgemeinmedizin 2008;84:321-6.

25 Shen M, He W, Li L. Incentives to use primary care and their impact on healthcare utilization: evidence using a public health insurance dataset in China. Soc Sci Med 2020;255:112981.

26 Wei X, Li H, Yang N, et al. Changes in the perceived quality of primary care in Shanghai and Shenzhen, China: a difference-indifference analysis. Bull World Health Organ 2015;93:407-16.

27 Wang X, Sun X, Birch S, et al. People-centred integrated care in urban China. Bull World Health Organ 2018;96:843-52.

28 Liu X, Xu J, Yuan B, et al. Containing medical expenditure: lessons from reform of Beijing public hospitals. BMJ 2019;365:I2369. 